\title{
Conformational Properties of the Amino Acid Residues L-Cysteine, L-Serine and L-Cystine
}

\author{
C. H. Görbitz \\ Department of Chemistry, University of Oslo, P.O. Box 1033, Blindern N-0315 Oslo 3, Nonway
}

Görbitz, C. H., 1990. Conformational Properties of the Amino Acid Residues L-Cysteine, L-Serine and L-Cystine. - Acta Chem. Scand. 44: 584-590.

The correlation between torsion angles of the main chain and the orientation of the side chain in the solid phase has been investigated for the amino acids L-cysteine, $\mathrm{L}$-serine and L-cystine. Information has been obtained from the Cambridge Structural Database.

In the crystal structures of cysteine and serine the torsion angle $N-C^{a}-C^{\prime}-N(\psi)$ is often close to 0 or $180^{\circ}$. When this is the case, $\mathrm{N}-\mathrm{C}^{\alpha}-\mathrm{C}^{\beta}-\mathrm{O}^{\gamma} / \mathrm{S}^{\gamma}\left(\chi^{1}\right)$ is almost exclusively in the vicinity of $60^{\circ}\left(g^{+}\right)$. When $\psi$ is in the interval $30-150^{\circ}$, only trans $(t)$ or gauche $e^{-}\left(g^{-}\right)$is observed. Thus, $\chi^{1}$ is strongly dependent on the conformation of the main chain for these residues. Force-field energy calculations agree reasonably well with the experimental results.

For L-cystine, $g^{-}$is more frequently observed than $g^{+}$at $\chi^{1} \cdot \chi^{2}$ and $\chi^{3}$ (disulfide bond) are both around $+1-85^{\circ}$. The sign sequences for the five torsion angles along the disulfide bridge $\left(\chi^{1}, \chi^{2}, \chi^{3}, \chi^{2 \prime}, \chi^{1 \prime}\right)$ are: cyclic peptides, --+-- or other; non-cyclic with twofold axis, +---+ or +++++ ; other non-cyclic, ----- or ++++ .

The connection between the values of the torsion angles $\varphi$ and $\psi$ for various secondary structures of a peptide chain, usually presented in the form of a Ramachandran map, is familiar to all peptide chemists. In contrast, the less obvious connection between main-chain conformation and allowed or preferred orientations of the side chain is only rarely commented upon. Most papers present the two accompanying sets of torsion angles as largely independent entities. There are, however, some theoretical studies ${ }^{1-3}$ which indicate that the presence of atoms beyond $\mathrm{C}^{\beta}$ in the side chain does have an effect on the allowed values of $\varphi$ and $\psi$. Conformational maps have been produced showing these restrictions. Furthermore, a survey of crystal structures of peptides ${ }^{4}$ has demonstrated that $\chi^{1}$ at $60^{\circ}$ is disfavored when $\psi$ deviates much from 0 or $180^{\circ}$ and that $\chi^{1}$ at $180^{\circ}$ is less frequently observed when $\psi$ is close to these angle values. Previous investigations ${ }^{5,6}$ have also indicated that in general the distribution between the three $\chi^{1}$ rotamers is slightly different in peptides and proteins. The purpose of this work was to investigate the existence of a connection between side-chain and main-chain conformations for the amino acids L-cysteine and L-serine. Conformational properties of the disulfide bridge in L-cystine have also been analyzed.

\section{Methodology}

All crystallographic data were retrieved from the Cambridge Structural Database (CSD, January 1989 release). ${ }^{7}$ The number of structures analyzed is 20 for serine, ${ }^{8-22}$ containing 26 crystallographically independent residues, 8 for cysteine,$^{23-30}$ containing 9 residues and 14 for cystine $e^{31-43}$ each containing one disulfide bridge, four of which have a twofold axis through the S-S bond. Structures in the first group all have $R$ factors less than 0.085 , whereas for cysteine three structures have $R$ factors in the range 0.09-0.14. Some of the cystine structures have $R$ factors up to 0.13 , but all have been retained due to the small number of molecules available. No side-chain disorder was allowed. In cases of duplicate structures, the more precise determination was used. Data for cysteine has been supplemented with two structures, ${ }^{44}$ and torsion angles for three D-serine

Table 1. References for REFCODes.

\begin{tabular}{lcllll}
\hline REFCOD & Ref. & REFCOD & Ref. & REFCOD & Ref. \\
\hline Serine & & PIVSMA & 18 & Cystine & \\
& & SERASC10 & 19 & & \\
BUFFEN10 & 8 & SERGL & 20 & BEWDIQ10 & 31 \\
BUFFIR10 & 8 & SERTYR10 & 21 & BICKON & 32 \\
CGPSAQ & 9 & FEPFOV & 22 & CYSMEC & 33 \\
COBXAS & 8 & & & CYSTBR & 34 \\
COBXEW & 8 & CySteine & & CYSTCL02 & 35 \\
CSEHSM & 10 & & & CYSTIN10 & 36 \\
CUJHIY & 11 & CYGNAI & 23 & DGLYCH01 & 37 \\
CUJHOE & 11 & CYSCLM10 & 24 & DUNLON & 38 \\
CYSESE & 12 & DLCYST & 25 & GAGDIB & 39 \\
DIYZOA & 13 & ECYSCU & 26 & LCSTIM & 40 \\
DLSERN11 & 14 & GLUTAS02 & 27 & LCYSCC & 41 \\
FERCRN10 & 15 & LCYSTN & 28 & LCYSTI10 & 42 \\
LALLSE & 16 & LCYSTN21 & 29 & LCYSTI11 & 43 \\
LSERIN10 & 17 & NALCYS10 & 30 & TANDEM30 & 32 \\
LSERMH10 & 14 & & & & \\
\hline
\end{tabular}


residues were inverted to the equivalent conformation of L-serine. Cystine structures include molecules where the residue is part of a large ring system, but not cyclo-cystine (Cys-Cys). The nomenclature and conventions used follow the recommendations of IUPAC..$^{45}$ When referring to a CSD entry, the database identification reference code (REFCOD) was used. REFCOD references are given in Table 1.

Energy minimizations were performed with the AMBER force field ${ }^{46,47}$ which is an integrated part of the SYBYL Version 5.2 computer program. ${ }^{48}$ Electrostatic interactions were used and all hydrogen atoms were included. The dielectric constant was set to 80 which should be appropriate for mimicking an aqueous molecular environment. The cut-off criteria was an energy change less than $0.00025 \mathrm{~kJ}$ $\mathrm{mol}^{-1}$. Conformational searches were carried out with the SEARCH function of the SYBYL program. Relatively short intramolecular contacts were permitted, down to 0.93 times the sum of the van der Waals' radii. Instead of the default geometry of the trans peptide bond, new parameters were calculated using 264 peptide bonds in 116 structures of $R$ factor $<0.075$ from the CSD. A list of references is available from the author on request.

\section{Description and discussion}

\section{Serine and cysteine}

$\chi^{1}$ and $\chi^{2}$. For the study of cysteine, only unsubstituted residues with a free $-\mathrm{SH}$ group were used. The distribution
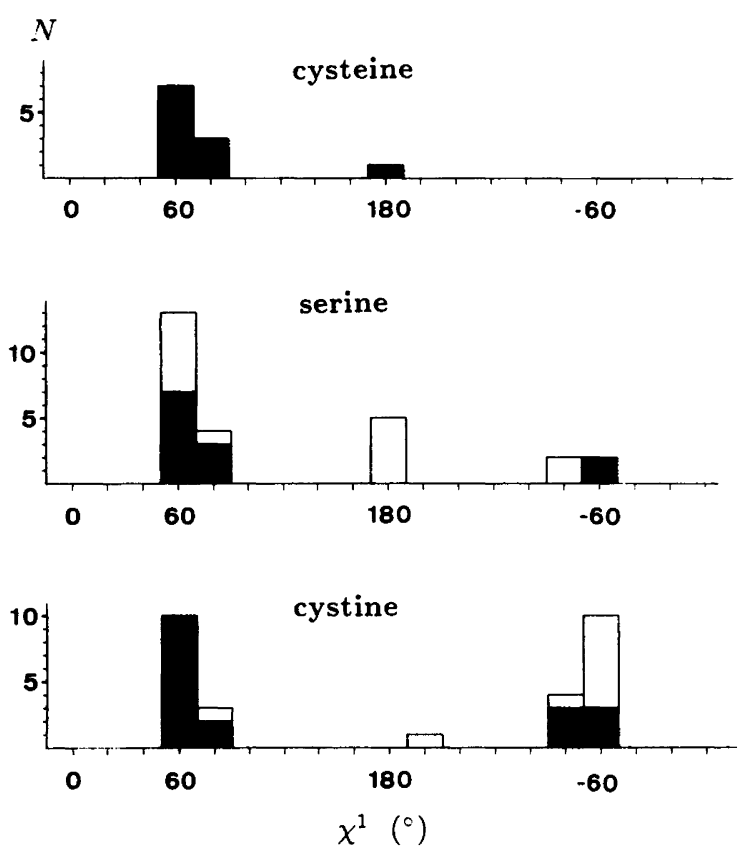

Fig. 1. $\chi^{1}$ distribution for cysteine, serine and cystine. The white and black columns represent residues in cyclic and non-cyclic molecules, respectively. In the diagram for cystine, molecules with a twofold axis are given double weight.
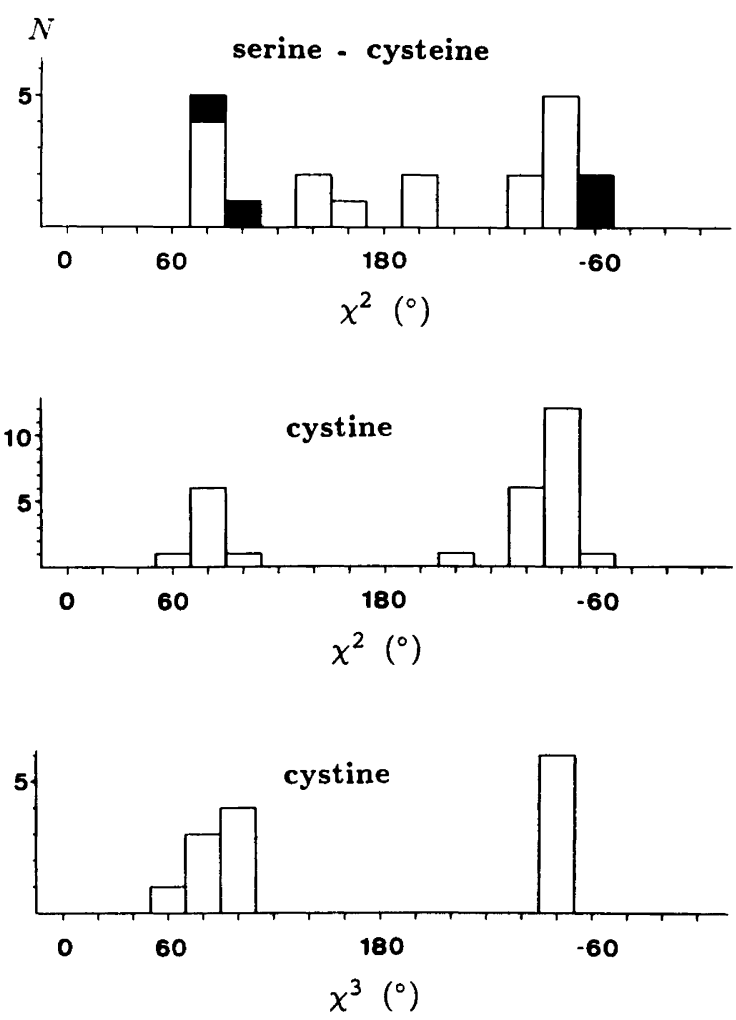

Fig. 2. $\chi^{2}$ distributions for cysteine (black)/serine (top) and cystine (middle) and $\chi^{3}$ distribution for cystine (bottom).

of $\chi^{1}$ (Fig. 1) shows a highly ( $>99.9 \%$ ) significant preference for the $g^{+}$conformation $(91 \%)$ which has not been described in earlier surveys. For serine the distribution also shows a preference for $g^{+}(65 \%)$, and upon removal of all residues which are part of cyclic systems, this preference is even more pronounced $(83 \%)$. The common distribution of $\chi^{2}$ for cysteine and serine is given in Fig. 2. Peaks are found around $+/-80^{\circ}$ and $+/-150^{\circ}$. It should be noted that the positions of hydrogen atoms may be subject to relatively large errors, and that the hydrogen bonding for serine, and to a lesser extent for cysteine, may conceal any inherent preferences of the terminal groups towards particular torsion angles.

Correlation with main-chain. Fig. 3 depicts the distribution of $\psi$ against $\chi^{1}$ for serine and cysteine. When the $\mathrm{N}-\mathrm{C}^{\alpha}-$ $\mathrm{C}^{\prime}-\mathrm{N}$ group is close to planar $\left(\psi\right.$ close to $0^{\circ}$ or $\left.180^{\circ}\right)$, the $g^{+}$ conformation is totally dominant. On the other hand, $g^{+}$is not observed for residues with $\psi$ in the interval $100-150^{\circ}$. The Ramachandran plot of $(\varphi, \psi)$ for 23 residues is shown in Fig. 4. It can be seen that all but two structures fit nicely into four well-defined groups. These may be described in more detail.

Group (A). $\psi$ is close to $180^{\circ}$ and $\varphi$ to $-164^{\circ}$ (one residue at $-136^{\circ}$ ). This group consists of three serine residues in large ring systems ( 2 CUJHIY, CUJHOE), as well as two $C$-terminal serines (DIYZOA, LALLSE) and one 


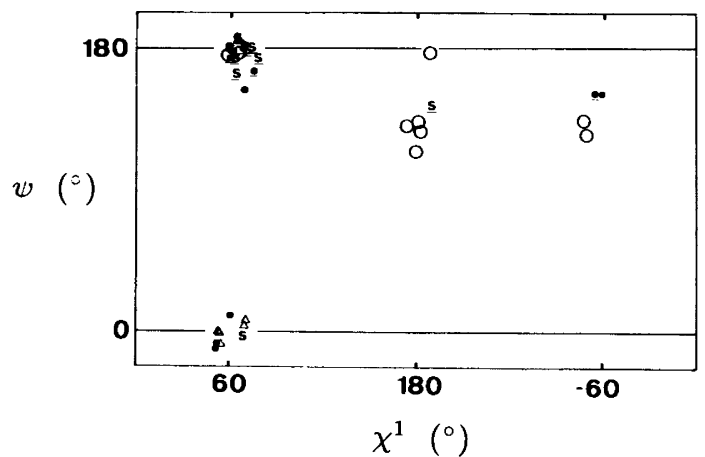

Fig. 3. Distribution of $\psi$ against $\chi^{1}$ for cysteine and serine. In Figs. 3 and 4 the following symbols are used: $\Delta$, Serine in cyclic dipeptide; $O$, Cyclic structure with serine; $\boldsymbol{O}$, Linear structure with serine; S, Cysteine in linear structure. Underlined symbols represent structures with $C$-terminal carboxy, carboxylate or ester groups. For these molecules $\psi_{T}{ }^{1}$ or $\psi_{T}{ }^{2}$ is plotted. In Fig. 3, the value closest to $180^{\circ}$ has been used, in Fig. 4 the value giving the better fit to one of the four groups indicated in the map.

$C$-terminal cysteine (NALCYS10). The conformation is very extended; $\psi$-values close to $180^{\circ}$ are in general quite rare. The $\chi^{1}$ distribution $g^{+}: t: g^{-}$is 5:1:0.

Group (B). $\psi$ is around $0^{\circ}$, and $\varphi$ is around $-80^{\circ}$. This is in the 'bridge region' connecting the regions for extended chain and helix in the Ramachandran plot. The parameters correspond to a type I $\beta$ turn, but the group consists of three $C$-terminal serine amides (BUFFEN10, BUFFIR10, COBXAS), one $C$-terminal serine methyl ester (COB$\mathrm{XEW}$ ) and glutathione ( $\gamma$-Glu-Cys-Gly, GLUTAS02), none of which are involved in such turns. All $\chi^{1}$ are $g^{+}$.

Group (C). $(\varphi, \psi)$ is around $\left(-55^{\circ}, 130^{\circ}\right)$ which are the parameters for the second residue in the type II $\beta$ turn. All serines are located in such $\beta$ turns in rather similar large

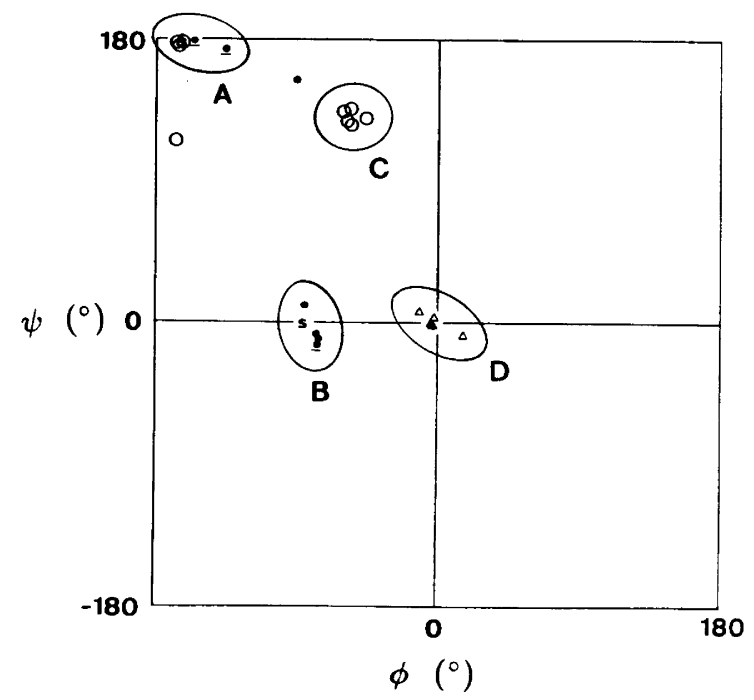

Fig. 4. Ramachandran plot of $(\varphi, \psi)$ for cysteine and serine. Letters refer to groups described in the text.

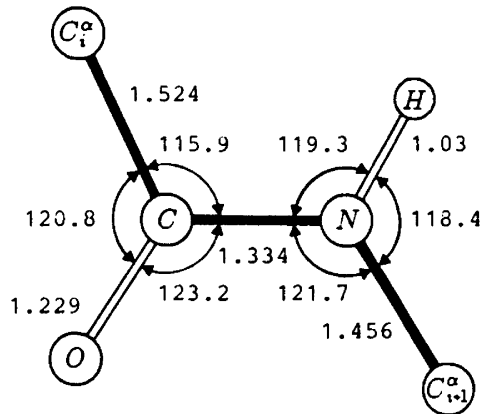

Fig. 5. Bond lengths $(\AA)$ and bond angles $\left(^{\circ}\right)$ of the trans peptide bond. Standard deviations for mean values are $0.001 \AA$ and $0.1^{\circ}$, respectively. For bond angles involving $\mathrm{H}$ the standard deviations are $0.3^{\circ}$. The $\mathrm{N}-\mathrm{H}$ value is derived from neutron diffraction studies, $X$-ray structures give $0.934(6) \AA$ for this bond length.

ring structures $(2 \cdot$ CUJHIY, CUJHOE, $2 \cdot$ FERCRN10). The $\chi^{1}$ distribution $g^{+}: t: g^{-}$is $0: 3: 2$.

Group (D). Cyclic dipeptides (dioxopiperazines), in which both $\varphi$ and $\psi$ necessarily are close to $0^{\circ}$ (CSEHSM, $2 \cdot$ CYSESE, SERTYR10, FEPFOV). Thus the connection between these two torsion angles in this group is of limited interest in this study, but it is still interesting that $\chi^{1}$ is invariably found in the $g^{+}$conformation. This group is not discussed further.

Computation of sterically allowed conformations. Earlier papers ${ }^{1-3}$ have documented that the presence of a $\mathrm{C}^{\gamma}$-atom leads to slightly different allowed regions of the Ramachandran map depending on which staggered position is occupied. To see if the $\chi^{1}$ populations described above could be
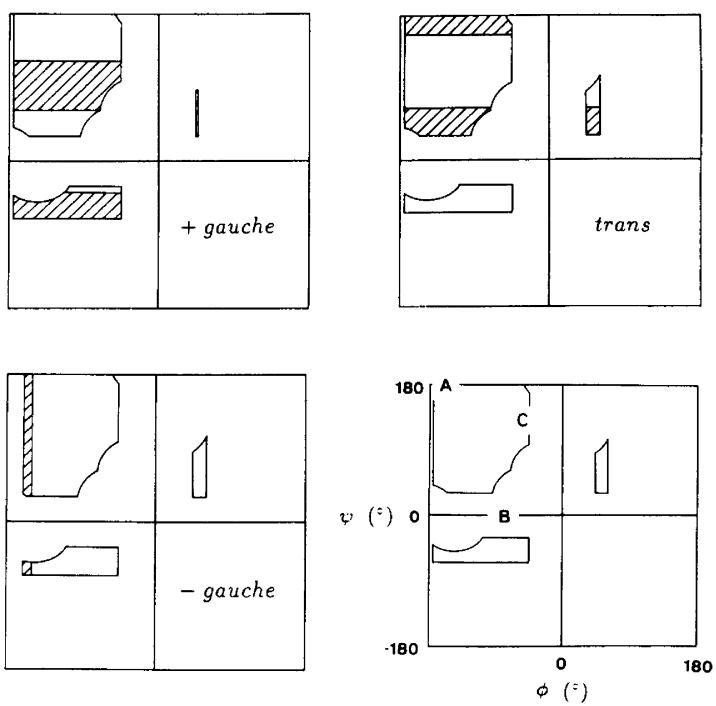

Fig. 6. Theoretical Ramachandran plots for cysteine and serine. Solid lines enclose allowed values of $\varphi$ and $\psi$ for each $\chi^{1}$ rotamer of serine, lined regions are disallowed for cysteine. 


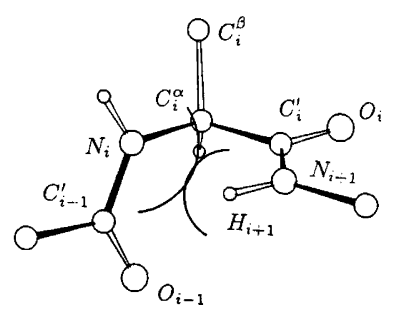

Scheme 1.

explained by such differences, similar maps were calculated for serine and cysteine. The molecules $N$-acetyl-L-Cys- $N$ methylamide and $N$-acetyl-L-Ser- $N$-methylamide were used as model peptides. The geometry of the trans peptide bond from a survey of crystal structures is given in Fig. 5. The values indicated were used during the search procedure except for the two angles involving the amide proton which were raised by $0.3^{\circ}$ (to 19.6 and $18.7^{\circ}$ ) to obtain a planar arrangement around the nitrogen atom. $\omega$ was $180^{\circ}$ and $\tau\left(\mathrm{C}^{\alpha}\right)\left(\mathrm{N}-\mathrm{C}^{\alpha}-\mathrm{C}^{\prime}\right)$ was kept at $111.0^{\circ}$. The results are shown in Fig. 6.

The maps for serine show that the differences between permitted regions for the three $\chi^{1}$ rotamers are marginal, and in most cases these can be neglected. The Ramachandran plots for cysteine however, demonstrate that the larger van der Waals' radius of a sulfur atom compared with an oxygen atom greatly reduces the rotational freedom of the side chain for this residue. In the experimental (A) conformation, $g^{+}$is the only allowed rotamer for cysteine, $g^{-}$and $t$ give too close contacts with $\mathrm{O}_{i-1}$ and $\mathrm{H}_{i+1}$, respectively. On the other hand, for serine all rotamers are allowed. (B) is apparently disallowed for both residues regardless of the orientation of the side chain. In this region, steric conflict exists between $\mathrm{N}_{i}$ and $\mathrm{H}_{i+1}$ (Scheme 1).

This short intramolecular contact may be relieved fairly easily by a small opening of $\tau\left(C^{\alpha}\right)$. Indeed, experimental results ${ }^{49}$ show that when $\psi$ is close to $0^{\circ}$, the mean value for $\tau\left(C^{\alpha}\right)$ is about $4^{\circ}$ larger than in the extended region $(\psi$ in the interval $120-170^{\circ}$ ). Making this adjustment, one finds that all rotamers are possible for both residues. This is also the case for $(C)$.

In an attempt to explain further the conformational preferences of $\chi^{1}$, the three main-chain configurations have been energy-minimized with the AMBER force field. In the first step $\varphi$ and $\psi$ were kept fixed to experimental values. $\chi^{1}$ was not fixed, but tended to change very little. In the next step all constraints were released to let the refinement proceed to the closest local minimum. The results are given in Table 2 .

The energies obtained from the constrained refinements generally give and adequate agreement with the experimental distributions which may be summarized as follows (1) Serine (A): $g^{-}$is not observed and is calculated to have the highest energy. The experimental preference for $g^{+}$ over $t$ is unexplained. (2) Serine (B): $t$ has high energy and is unobserved. The preference for $g^{+}$over $g^{-}$is unexplained. (3) Serine (C): $g^{+}$is not observed and has the highest energy. $t$ and $g^{-}$are both observed, but a discrepancy exists as $t$ is calculated to have significantly higher

Table 2. Torsion angles $\left(^{\circ}\right)$ and calculated energies $\left(\mathrm{kJ} \mathrm{mol}^{-1}\right)$ for minimized conformers of serine and cysteine.

\begin{tabular}{|c|c|c|c|c|c|c|c|c|c|}
\hline \multirow[t]{2}{*}{ Residue } & \multirow{2}{*}{$\begin{array}{l}\text { Main } \\
\text { chain }\end{array}$} & \multicolumn{4}{|c|}{ Constrained refinement } & \multicolumn{4}{|c|}{ Free refinement } \\
\hline & & $\varphi$ & $\psi$ & $\chi^{1}$ & $E$ & $\varphi$ & $\psi$ & $x^{1}$ & $E$ \\
\hline Serine & (A) & $\begin{array}{l}-164 \\
-164 \\
-164\end{array}$ & $\begin{array}{l}176 \\
176 \\
176\end{array}$ & $\begin{array}{r}60 \\
180 \\
-60\end{array}$ & $\begin{array}{r}0.0^{a} \\
0.5 \\
16.6\end{array}$ & $\begin{array}{l}-169 \\
-169 \\
-140\end{array}$ & $\begin{array}{r}178 \\
-171 \\
163\end{array}$ & $\begin{array}{r}55 \\
-176 \\
-57\end{array}$ & $\begin{array}{l}3.8 \\
0.0 \\
6.8\end{array}$ \\
\hline Serine & (B) & $\begin{array}{l}-80 \\
-80 \\
-80\end{array}$ & $\begin{array}{l}-6 \\
-6 \\
-6\end{array}$ & $\begin{array}{r}60 \\
180 \\
-60\end{array}$ & $\begin{array}{r}0.2 \\
31.4 \\
0.0\end{array}$ & $\begin{array}{l}-66 \\
-57 \\
-48\end{array}$ & $\begin{array}{l}-48 \\
-44 \\
-40\end{array}$ & $\begin{array}{r}44 \\
-175 \\
-44\end{array}$ & $\begin{array}{r}2.3 \\
32.6 \\
0.0\end{array}$ \\
\hline Serine & (C) & $\begin{array}{l}-55 \\
-55 \\
-55\end{array}$ & $\begin{array}{l}130 \\
130 \\
130\end{array}$ & $\begin{array}{r}60 \\
180 \\
-60\end{array}$ & $\begin{array}{r}20.5 \\
18.0 \\
0.0\end{array}$ & $\begin{array}{l}-79 \\
-64 \\
-71\end{array}$ & $\begin{array}{r}166 \\
136 \\
64\end{array}$ & $\begin{array}{r}45 \\
-174 \\
-50\end{array}$ & $\begin{array}{r}21.3 \\
32.3 \\
0.0^{b}\end{array}$ \\
\hline Cysteine & (A) & $\begin{array}{l}-164 \\
-164 \\
-164\end{array}$ & $\begin{array}{l}176 \\
176 \\
176\end{array}$ & $\begin{array}{r}60 \\
177 \\
-60\end{array}$ & $\begin{array}{r}0.0 \\
9.9 \\
10.1\end{array}$ & $\begin{array}{l}-168 \\
-158 \\
-156\end{array}$ & $\begin{array}{r}163 \\
99 \\
102\end{array}$ & $\begin{array}{r}69 \\
172 \\
-75\end{array}$ & $\begin{array}{r}0.2 \\
0.0 \\
26.2\end{array}$ \\
\hline Cysteine & (B) & $\begin{array}{l}-80 \\
-80 \\
-80\end{array}$ & $\begin{array}{l}-6 \\
-6 \\
-6\end{array}$ & $\begin{array}{r}60 \\
180 \\
-60\end{array}$ & $\begin{array}{r}0.0 \\
4.5 \\
17.2\end{array}$ & $\begin{array}{l}-75 \\
-64 \\
-65\end{array}$ & $\begin{array}{l}-21 \\
-43 \\
-30\end{array}$ & $\begin{array}{r}70 \\
180 \\
-65\end{array}$ & $\begin{array}{r}1.9 \\
0.0 \\
21.2\end{array}$ \\
\hline Cysteine & (C) & $\begin{array}{l}-55 \\
-55 \\
-55\end{array}$ & $\begin{array}{l}130 \\
130 \\
130\end{array}$ & $\begin{array}{r}60 \\
180 \\
-60\end{array}$ & $\begin{array}{r}20.5 \\
0.0 \\
24.7\end{array}$ & $\begin{array}{l}-67 \\
-66 \\
-65\end{array}$ & $\begin{array}{l}142 \\
129 \\
125\end{array}$ & $\begin{array}{r}68 \\
179 \\
-66\end{array}$ & $\begin{array}{r}13.4 \\
0.0 \\
22.5\end{array}$ \\
\hline
\end{tabular}

${ }^{a}$ Lowest energy staggered position set to $E=0.0 .{ }^{b}$ Stabilized by an intramolecular hydrogen bond. 
energy than $g^{-}$. (4) Cysteine: the experimental material is to limited to allow any comparison with the theoretical data.

The results of the free refinement show that considerable alterations take place when the constraints are released. Molecules in the almost planar (B) conformation with $\psi=$ $-6^{\circ}\left(\varphi=-80^{\circ}\right)$ are shifted to positions in a $(\varphi, \psi)$ map close that of an $\alpha$-helix $\left(-58^{\circ},-47^{\circ}\right)$. For (C) too, substantial shifts are observed. A particular case is serine (C) $g^{-}$which ends up with an intramolecular hydrogen bond between $\mathrm{O}_{i-1}$ and $\mathrm{N}_{i+1}$.

In short, it seems that due to the large shifts for $\varphi$ and $\psi$ in the free refinement, the contrained refinement is most appropriate for studies of $\chi^{1}$ distributions for a set of $(\varphi, \psi)$ values. The considerations above may then explain some of the experimental results, but at the same time several observations remain unresolved. Taking into account crystallattice forces may possibly improve the results, ${ }^{50}$ but reliable theoretical rotamer populations are no doubt very hard to obtain. Finally, it should also be born in mind that this investigation is based on a limited number of experimental structures, and that some of the features described in the text may eventually turn out to be statistical coincidences.

\section{Cystine}

$\chi^{1}$. The distribution shown for cystine (Fig. 1) deviates significantly from those of cysteine and serine. The trans conformation is still quite rare, but for this residue $g^{-}$is dominant over $g^{+}$.

$\chi^{2}$ and $\chi^{3}$. The distributions of $\chi^{2}$ and $\chi^{3}$ (disulfide bond) are depicted in Fig. 2. The trans rotamer is absent for these two torsion angles, and the gauche rotamers are significantly distorted from $+/-60^{\circ}$ to positions at approximately $+1-85^{\circ}$.

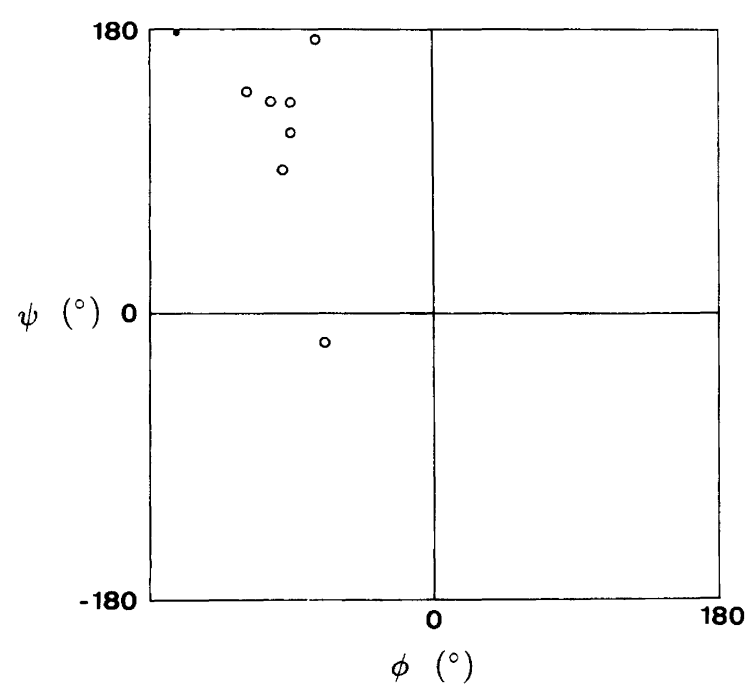

Fig. 7. Ramachandran plot of $(\varphi, \psi)$ for cystine: $O$, cyclic structures; 0 , non-cyclic structure.

Correlation with the main chain. A Ramachandran plot is given in Fig. 7. There are only 8 points in the diagram, of which 7 represent residues in cyclic systems (BEWDIQ10, 2-BICKON, DUNLON, GAGDIB, 2-TANDEM30). The scatter is quite wide, and the points are not located in the groups described for serine and cysteine. The only non-cyclic structure however (DGLYCH01), fits nicely with the parameters for group (A) with the side chain in the $\mathrm{g}^{+}$conformation. There is no indication in this material that the conformational preferences for $\left(\varphi, \psi, \chi^{1}\right)$ and $\left(\varphi^{\prime}, \psi^{\prime}\right.$, $\left.\chi^{1 \prime}\right)$ are any different from those of a single cysteine residue. The appearance of the Ramachandran plot is different from the one in Fig. 4 because most of the points represent cyclic systems. Severe restrictions limit the possible conformations of the disulfide bridge in these molecules.

Table 3. Torsion angles $\left(^{\circ}\right)$ in the disulfide bridge in cystine structures with separations between $C^{\alpha}$ atoms $(\AA)$.

\begin{tabular}{|c|c|c|c|c|c|c|c|c|c|c|}
\hline Compound & NCCS & ccss & cssc & SSCC & $\operatorname{SCCN}$ & Signs & $2^{a}$ & $0^{b}$ & $C^{\alpha} \ldots C^{\alpha}$ & REFCOD \\
\hline Boc-Cys-Pro-Aib-Cys- $\mathrm{NHCH}_{3}$ & -169.1 & 138.7 & 81.5 & 73.3 & -71.3 & $t-++-$ & & * & 5.3 & EWDIQ10 \\
\hline $\begin{array}{l}\text { Tandem } \cdot 14 \mathrm{H}_{2} \mathrm{O} \\
\text { L-Cystine dimethyl ester } \cdot 2 \mathrm{HCl} \cdot \mathrm{H}_{2} \mathrm{O} \\
\text { L-Cystine } \cdot 2 \mathrm{HBr} \\
\text { L-Cystine } \cdot 2 \mathrm{HCl} \\
\text { L-Cystine } \cdot 2 \mathrm{HBr} \cdot 2 \mathrm{H}_{2} \mathrm{O} \\
\mathrm{N}, \mathrm{N}^{\prime} \text {-Diglycyl-L-cystine } \cdot 2 \mathrm{H}_{2} \mathrm{O} \\
\text { Pressinoic acid } \cdot \mathrm{H}_{2} \mathrm{O} \\
\text { Boc-Cys-Val-Aib-Ala-Leu-Cys- } \mathrm{NHCH}_{3}\end{array}$ & $\begin{array}{r}-53.9 \\
-75.9 \\
70.6 \\
68.7 \\
-54.9 \\
60.1 \\
79.6 \\
-54.9\end{array}$ & $\begin{array}{r}-87.8 \\
-79.2 \\
84.5 \\
-88.5 \\
-82.3 \\
-95.2 \\
92.9 \\
-101.1\end{array}$ & $\begin{array}{r}101.7 \\
-84.4 \\
77.6 \\
-82.5 \\
-79.8 \\
-84.4 \\
95.4 \\
101.2\end{array}$ & $\begin{array}{r}-84.2 \\
-77.4 \\
84.5 \\
-88.5 \\
-70.0 \\
-95.2 \\
-70.7 \\
-84.1\end{array}$ & $\begin{array}{r}-61.0 \\
-51.7 \\
70.6 \\
68.7 \\
-85.3 \\
60.1 \\
-60.9 \\
-63.1\end{array}$ & $\begin{array}{l}--+-- \\
----- \\
+++++ \\
+---+ \\
----- \\
+---+ \\
+++-- \\
--+--\end{array}$ & * & $\stackrel{\text { * }}{*}$ & $\begin{array}{l}3.8 \\
5.8 \\
5.0 \\
6.1 \\
5.7 \\
6.1 \\
5.0 \\
4.0\end{array}$ & $\begin{array}{l}\text { BICKON } \\
\text { CYSMEC } \\
\text { CYSTBR } \\
\text { CYSTCL02 } \\
\text { CYSTIN10 } \\
\text { DGLYCH01 } \\
\text { DUNLON } \\
\text { GAGDIB }\end{array}$ \\
\hline $\begin{array}{l}\text { L-Cystine diamide } \cdot 2 \mathrm{HCl} \\
\text { L-Cystine } \cdot 2 \mathrm{HCl} \cdot 2 \mathrm{H}_{2} \mathrm{O} \\
\text { L-Cystine (hexagonal form) } \\
\text { L-Cystine (tetragonal form) } \\
\text { Tandem } 12 \mathrm{H}_{2} \mathrm{O}\end{array}$ & $\begin{array}{r}65.0 \\
-55.8 \\
55.2 \\
64.3 \\
-52.0\end{array}$ & $\begin{array}{r}-94.6 \\
-80.6 \\
81.6 \\
75.1 \\
-99.9\end{array}$ & $\begin{array}{r}-81.4 \\
-79.9 \\
73.7 \\
69.3 \\
99.7\end{array}$ & $\begin{array}{r}-94.6 \\
-70.8 \\
81.6 \\
66.9 \\
-79.1\end{array}$ & $\begin{array}{r}65.0 \\
-85.1 \\
55.2 \\
51.2 \\
-64.0\end{array}$ & $\begin{array}{l}+---+ \\
----- \\
+++++ \\
+++++ \\
--+--\end{array}$ & * & * & $\begin{array}{l}6.1 \\
5.7 \\
5.9 \\
5.6 \\
3.9\end{array}$ & $\begin{array}{l}\text { LCSTIM } \\
\text { LCYSCC } \\
\text { LCYSTI10 } \\
\text { LCYSTI11 } \\
\text { TANDEM30 }\end{array}$ \\
\hline
\end{tabular}

${ }^{a}$ Molecule with a twofold axis through the S-S bond. ${ }^{b}$ Cyclic peptides. 
Table 4. Allowed sign sequences for $\chi^{1} \chi^{2} \chi^{3} \chi^{21} \chi^{11}$ torsion angles in the disulfide bridge of cystine. Signs used for the values are (in ${ }^{\circ}$ ): $+, \chi^{2}, \chi^{3}, \chi^{21}[70,100]$ or $\chi^{1}, \chi^{11}[50,70] ;-, \chi^{2}, \chi^{3}, \chi^{2 \prime}[-70,-100]$ or $\chi^{1}, \chi^{11}[-50,-70] ; t, \chi^{1}, \chi^{11}[170,190]$.

\begin{tabular}{|c|c|c|c|c|c|c|c|}
\hline \multirow{2}{*}{$\frac{\chi^{2} \chi^{3} \chi^{2 \prime}}{+++}$} & \multirow{2}{*}{$\frac{\text { Total }^{a}}{6}$} & \multicolumn{6}{|c|}{ Sign sequences ${ }^{b}$} \\
\hline & & +++++ & $+++t$ & ++++- & $t+++t$ & $t+++-$ & -+++- \\
\hline--- & 6 & +---+ & $+---t$ & +---- & $t---t$ & $t----$ & ----- \\
\hline++- & 9 & +++-- & $t++--$ & -++-- & & & \\
\hline+-+ & 6 & $t+-+t$ & & & & & \\
\hline+-- & 9 & $t+--+$ & $t+--t$ & $t+---$ & & & \\
\hline-+- & 6 & --+-- & & & & & \\
\hline Sum & 42 & 26 & & & & & \\
\hline
\end{tabular}

${ }^{a}$ Theoretical number of sign combinations. Symmetry has been included; $++++-=-++++$ and so on. ${ }^{b}$ Readily accessible conformations.

Disulfide bridge conformation. There are three possible rotamers at $\chi^{1}$, and two each at $\chi^{2}$ and $\chi^{3}$ giving 42 possible combinations for the bridge $\chi^{1} \chi^{2} \chi^{3} \chi^{21} \chi^{11}$ (symmetry included, see below). Some of these are prohibited due to steric hindrance, and only four have been found more than once in crystal structures (Table 3 ).

In the cyclic systems encompassing 14- and 20-membered rings, conformations of the disulfide bridge which give relatively short $C^{\alpha}-C^{\alpha}$ separations are always preferred. In particular, the sign combination --+-- , called the short right-hand hook, occurs on three different occasions. The left-hand spiral - - - - and the right-hand spiral +++++ are both observed in three structures. The former is the predominant conformation in proteins. ${ }^{51}$ The sign sequence +---+ is seen in three structures of noncyclic molecules, all having a twofold axis through the central S-S bond. Even when crystallographic symmetry is not present, there seems to be a marked tendency for symmetry at the $S-S$ bond with respect to the sign of the torsion angles. Only two structures exist where this is not the case.

For the C-S-S-C torsion angle, previous investigations give peaks in the distribution for the values -90 and $90^{\circ} .{ }^{51}$ It is thus rather peculiar that in Table 3 , no values are indicated in the intervals $\langle-85,-95\rangle$ and $<85,95\rangle$. The number of structures is however, too limited for one to tell if this observation has any significance.

Theoretical calculations. For the $\mathrm{CH}_{2}-\mathrm{S}-\mathrm{S}-\mathrm{CH}_{2}$ torsion angle AMBER combines a threefold and a twofold potential to ensure the well-known gauche tendency. However, for $\mathrm{C}^{\alpha}-\mathrm{C}^{\beta}-\mathrm{S}-\mathrm{S}$ only $\mathrm{X}-\mathrm{CH}_{2}-\mathrm{S}-\mathrm{X}$ torsional parameters are available which describe a standard threefold potential. Evidently, these are inadequate for reproducing experimental values of $\chi^{2}$ in cystine. Therefore, no energy calculations on conformations of the disulfide bridge have been performed. Instead the properties of cystine have been investigated in a more simple manner. In this procedure, all five torsion angles were varied simultaneously with $\chi^{1}$ and $\chi^{1 \prime}$ set to one of the three intervals $[50,70],[170,190]$ or $[-50,-70]$ while $\chi^{2}, \chi^{3}$ and $\chi^{21}$ were confined to the experimental intervals $[70,100]$ and $[-70,-100]$. Table 4 gives a complete list of allowed sign combinations. It can be seen that only 26 out of 42 conformations are easily accessible. In particular, structures in which the three central bonds have sign sequences +++ or --- have extended conformational freedom for $\chi^{1}$ and $\chi^{1 \prime}$. It should be noted that sign combinations other than those indicated in Table 4 may occur if the torsion angles deviate substantially from the values normally observed. An example is the structure of BEWDIQ10 with a rather unique $\mathrm{C}-\mathrm{C}-\mathrm{S}-\mathrm{S}$ torsion angle of $-139^{\circ}$. The sign combination is $t-++-$, which is not included in Table 4. The ring system in this molecule is rather strained, and it seems very unlikely that the same conformation would be found in a non-cyclic molecule.

\section{Concluding remarks}

It is rather surprising to see how the introduction of a serine or cysteine residue into a linear peptide seems to lock the main chain into one of only two distinct conformations in the solid phase, with the type II $\beta$ turn accounting for a third possibility in cyclic compounds. Furthermore a firm connection exists between the conformation of the side chain and the main chain. The serine $\chi^{1}$ distribution in proteins ${ }^{6}$ is $0.48: 0.24: 0.29$ for $g^{+}: t: g^{-}$, which deviates from the figures for serine in this survey $(0.65: 0.19: 0.15)$. This may be attributed to the fact that most residues in peptides are in well-defined conformations with a preference for $\mathrm{g}^{+}$, in proteins a large part (ca. $41 \%)^{52}$ of the residues are in reverse turns where the preference may be tilted towards $t$ and $g^{-}$conformations.

A similar argument may be used to explain the higher percentage of $t$ and $g^{-}$rotamers for cysteine/cystine in proteins. The combined (major part is cystine) distributions $g^{+}: t: g^{-}$is $0.14: 0.25: 0.61,{ }^{6}$ figures presented in this work for peptides are 0.91:0.00:0.09 and 0.46:0.04:0.50 for cysteine and cystine, respectively. The cystine residues play a crucial role in the folding of many proteins by virtue of their ability to form links between different polypeptide chains. Short interchain distances may then impose the same restrictions on the sign combination along the disulfide bridge as described above for the smaller cyclic molecules. 


\section{References}

1. Ramachandran, G. N., Ramakrishnan, C. and Venkatachalam, C. M. Biopolymers 3 (1965) 591.

2. Leach, S. J., Némethy, G. and Scheraga, H. A. Biopolymers 4 (1966) 369.

3. Némethy, G., Leach, S. J. and Scheraga, H. A. J. Phys. Chem. 70 (1966) 998.

4. Hseu, T. H. and Wang, C. J. Chin. Biochem. Soc. 10 (1981) 43.

5. Benedetti, E., Morelli, G., Némethy, G. and Scheraga, H. A. Int. J. Pept. Protein Res. 22 (1983) 1.

6. Ponder, J. W. and Richards, F. M. J. Mol. Biol. 193 (1987) 775 .

7. Allen, F. H., Bellard, S., Brice, M. D., Cartwright, B. A., Doubleday, A., Higgs, H., Hummelink, T., Hummelink-Peters, B. G., Kennard, O., Motherwell, W. D. S., Rodgers, J. R. and Watson, D. G. Acta Crystallogr., Sect. B 35 (1979) 2331.

8. Aubry, A., Ghermani, N. and Marraud, M. Int. J. Pept. Protein Res. 23 (1984) 113.

9. Karle, I. L. J. Am. Chem. Soc. 101 (1979) 181.

10. Cotrait, M. and Ptak, M. Acta Crystallogr., Sect. B 34 (1978) 528.

11. Barnes, C. L., Hossain, M. B., Jalal, M. A. F., Eng-Wilmot, D. L., Grayson, S. L., Benson, B. A., Agarwal, S. K., Mocherla, R. and van der Helm, D. Acta Crystallogr., Sect. C 41 (1985) 341

12. Fava, G. G., Belicchi, M. F., Marchelli, R. and Dossena, A. Acta Crystallogr., Sect. B 37 (1981) 625.

13. Suresh, C. G., Vijayan, M. Int. J. Pept. Protein Res. 26 (1985) 329.

14. Frey, M. N., Lehman, M. S., Koetzle, T. F. and Hamilton, W. C. Acta Crystallogr., Sect. B 29 (1973) 876.

15. Barnes, C. L., Eng-Wilmot, D. L. and van der Helm, D. Acta Crystallogr., Sect. C 40 (1984) 922.

16. Jones, P. G., Falvello, L. and Kennard, O. Acta Crystallogr., Sect. B 34 (1978) 1939.

17. Benedetti, E., Pedone, C. and Sirigu, A. Gazz. Chim. Ital. 103 (1973) 555.

18. Aubry, A., Protas, J., Marraud, M. and Neel, J. Acta Crystallogr., Sect. B 32 (1976) 2749.

19. Sudhakar, V., Bhat, T. N. and Vijayan, M. Acta Crystallogr., Sect. B $36(1980) 125$

20. Jones, P. G., Falvello, L. and Kennard, O. Acta Crystallogr., Sect. B 34 (1978) 2379.

21. Lin, C.-F. and Webb, L. E. J. Am. Chem. Soc. 95 (1973) 6803.

22. Symersky, J., Blaha, K. and Langer, M. Acta Crystallogr., Sect. C 43 (1987) 303.

23. Dryer, H. B. Acta Crystallogr. 4 (1951) 42.

24. Ayyar, R. R. Z. Kristallogr. 126 (1968) 227.

25. Freeman, H. C. and Moore, C. J. Acta Crystallogr., Sect. B 33 (1977) 2690.

26. Haas, D. J. Acta Crystallogr. 19 (1965) 860.
27. Görbitz, C. H. Acta Chem. Scand., Ser. B 41 (1987) 362.

28. Harding, M. M. and Long, H. A. Acta Crystallogr., Sect. B 24 (1968) 1096.

29. Kerr, K. A. and Ashmore, J. P. Acta Crystallogr., Sect. B 29 (1973) 2124.

30. Takusagawa, F., Koetzle, T. F., Kou, W. W. H. and Parthasarathy, R. Acta Crystallogr., Sect. B 37 (1981) 1591.

31. Ravi, A., Prasad, B. V. V. and Balaram, P. J. Am. Chem. Soc. 105 (1983) 105.

32. Hossain, M. B., van der Helm, D., Olsen, R. K., Jones, P. G., Sheldrick, G. M., Egert, E., Kennard, O., Waring, M. J. and Viswamitra, M. A. J. Am. Chem. Soc. 104 (1982) 3401.

33. Vijayalakshmi, B. K. and Srinivasan, R. Acta Crystallogr., Sect. B 31 (1975) 993.

34. Ananthakrishnan, N. and Srinivasan, R. Indian J. Pure Appl. Phys. 2 (1964) 62.

35. Jones, D. D., Bernal, I., Frey, M. N. and Koetzle, T. F. Acta Crystallogr., Sect. B 30 (1974) 1220.

36. Rosenfield, R. E., Jr. and Parthasarathy, R. Acta Crystallogr., Sect. B 31 (1975) 816.

37. Stallings, W. C., Jr. and Donohue, J. Acta Crystallogr., Sect. B 32 (1976) 1916.

38. Langs, D. A., Smith, G. D., Stezowski, J. J. and Hughes, R. E. Science 232 (1986) 1240.

39. Karle, I. L., Kishore, R., Raghothama, S. and Balaram, P. J. Am. Chem. Soc. 110 (1988) 1958.

40. Chaney, M. O. and Steinrauf, L. K. Acta Crystallogr., Sect. B 24 (1968) 1564.

41. Kominami, S., Riesz, P., Akiyama, T. and Silverton, J. V. J. Chem. Phys. 80 (1976) 203.

42. Oughton, B. M. and Harrison, P. M. Acta Crystallogr. 12 (1959) 396.

43. Chaney, M. O. and Steinrauf, L. K. Acta Crystallogr., Sect. B 30 (1974) 711.

44. Görbitz, C. H. Acta Chem. Scand., Ser. B 43 (1989) 871.

45. IUPAC-IUB Joint Commission on Biochemical Nomenclature Eur. J. Biochem. 138 (1984) 9.

46. Weiner, P. and Kollman, P. A. J. Comput. Chem. 2 (1981) 287.

47. Weiner, S. J., Kollman, P. A., Case, D. A., Singh, U. C., Ghio, C., Alagona, G., Profeta, S., Jr. and Weiner, P. J. Am. Chem. Soc. 106 (1984) 765.

48. Tripos Associates Inc., St. Louis, Missouri.

49. Ashida, T., Tsunogae, Y., Tanaka, I. and Yamane, T. Acta Crystallogr., Sect. B 43 (1987) 212.

50. Lii, J.-H., Gallion, S., Bender, C., Wikström, H., Allinger, N. L., Flurchick, K. M. and Teeter, M. M. J. Comput. Chem. 10 (1989) 503.

52. Thornton, J. M. J. Mol. Biol. 151 (1981) 261.

53. Matthews, B. W. In: Neurath, H. and Hill, R. L., Eds., The Proteins, 3rd ed., Academic Press, New York 1977, Vol. 3.

Received October 27, 1989. 